$\begin{array}{lcc}\text { Nepal Journal of Multidisciplinary Research (NJMR) } & \text { ISSN: 2645-8470 (Paper) } \\ \text { Volume 2, No. } 3 & \text { September } 2019 & \text { ISSN: 2705-4691 (Online) }\end{array}$

DOI : https://doi.org/10.3126/njmr.v2i3.26974

\title{
Strategies to Stimulate the Economy of Contemporary Nepali Theatre
}

A case study to identify essential marketing model for Nepali Theatre

\author{
Deepesh Paudel \\ deepeshpaudel@gmail.com
}

\begin{abstract}
The contemporary Nepali theatre has stood at the crossroads at various junctures in time. Theatre institutions have frequently struggled for survival, primarily due to the inflating financial pressures and myopic strategic focus. For several of them, it has consequentially led them to complete shutdown. A gradually growing audience base hasn't been able to fully assure sustenance to the industry stakeholders. With such impending uncertainty hovering over the industry, theatre companies in Nepal are challenged to profitably sustain in the burgeoning entertainment industry. Sensing the imminent necessities, this paper introduces an interdisciplinary intervention by providing proven roadmaps for contemporary theatre players in Nepal. All of these strategies are derived and tailored from the domains of business and marketing. More specifically, the crux is fixated around the marketing mix model, devised by Neil Borden in the 1950s. Extracting pivotal arguments and findings from a variety of researches and studies conducted all around the world, the paper in hand attempts to synchronize conceptual underpinnings of the theories with pragmatic contexts of modern-day Nepali theatre. And before providing potential solutions, the author has also peeked into the existing economic landscape of contemporary Nepali theatre in order to identify the business related bottlenecks of the industry.
\end{abstract}

Keywords: Contemporary Nepali Theatre, Marketing Mix, Service Sector, Strategies

\section{Introduction}

A cursory glance at the plethora of scholarly works uncovers the multifarious definitions of theatre-art. Most of these interpretations explain theatre as an abstract, complex and virtuous form of expression. Many also build narratives around the imperatives of historical value, socio-cultural and political elements, and artistic solemnity possessed by the dramatic art form. This sacred undertone in defining theatre as a field of gravitas, although it appears to be justifiable, often overlooks another crucial dimension, which is the commercial operation and sustainability of the age-old platform. Acknowledging and analyzing what other scholars have already discussed, this paper stresses on the fact that theatre institutions should find apt motivation and strategies to stimulate the finances, not only for mere threshold survival but also for profit maximization and sectorial growth. It also identifies marketing mix strategies to incentivize the sector. In order to make the study more specific, I've selected Nepali theatre and its business and financial landscape as the core subject.

\section{A scant focus on the commerciality}

Of the few works aimed at covering the commercial significance of theatre operations, Iji (2007) interestingly places the dyad consisting 'business of theatre' and 'theatre of business' at the center of the analysis, where both aspects -- artistic goal along with stock-in-trade of the profession-- are put forward as ideals of modern day theatre. In doing so, the author conveniently establishes a correlation between the arts and commerce of theatre although merely offers adequate space to justify the essentiality of the latter aspect. The leveraging on historical, cultural and political anecdotes of multiple plays somewhat overshadows the 


\section{Nepal Journal of Multidisciplinary Research (NJMR) ISSN: 2645-8470 (Paper) Volume 2, No. 3 \\ September 2019 \\ ISSN: 2705-4691 (Online)}

proposed claim of regarding business and finance as pivotal facets in theatre. In fact the idea of categorizing the 'theatre of business' as entertainment-for-entertainment sake makes the discussion skewed.

Walmsley (2011), however, takes an altogether different route in investigating the dynamics of the theatre sector. The conceptual underpinning borrowed from subjects like consumer behavior, marketing and business in general supports in considering theatre as a service industry. Knell's (2005) reflections through the art of dying also pinpoints the dire circumstances bought to the field of theatre due to improper handling of funding and a lackluster management of the theatre. Despite being more tilted towards the funding schemes and modus operandi of theatre in the United Kingdom, Knell's work lays a foundation on which modern concepts of business models and strategic marketing can be experimented.

\section{The Economic Landscape of Nepali Theatre Industry}

Before drafting executable marketing strategies that can stimulate the business and economy of present-day Nepali theatre, one has to be cognizant of the various chronicles of theatre existence and operations in Nepal. In his book Nepali Theatre as I see it, Abhi Subedi (2006), playwright and academician, brings to light the cross-pollinated making of Nepali theatre. It is evident that Nepali theatre has evolved to its current state by absorbing sociopolitical, architectural, technological, historical, and religious happenings occurring in various periodic zones. Elucidating the chronological transformation (starting from the $5^{\text {th }}$ century) of the monumental theatre heritage in Nepal is neither pragmatically possible nor an intended approach for this essay. To paint a succinct picture of Nepali theatre and its economic backdrop, the industry has been visibly distinguished into three epochs: (i) During the Rana oligarchy (1846-1951), (ii) During the party-less Panchayat system (1960-1990), and (iii) Era of contemporary theatre after the establishment of Aarohan Gurukul (Rijal, 2015).

The 104 year-old Rana oligarchies stagnated Nepal's quintessential sectorial progress. Many blame the same autocratic system for pushing the state back in areas like education, agriculture, industrial and trade (Singh, 2004). Theatre in Nepal suffered similar fate back then. Outright restrictions on freedom and expression, which are considered as primary ingredient of theatre-art, by the feudal machinery meant that there was no mobility of human thoughts and voices. Nightlives were completely curtailed through imposing curfews. Under such extreme rigidity, the vibrancy of Nepali theatre, which before the Ranas was seen in different celebratory customs, ceased within the four walls of their palaces. These tyrant rulers, however, had a fondness for theatre and performing arts, which is corroborated by the presence of a theatre hall in each of their palaces (Rijal, 2015). When the only objective of theatre was to entertain the rulers of the nation, concerns regarding its economic viability and artists' and industry's financial return were of no significance. Many thespians of that period have even shared their battles of financial hardships, citing the insufficient remuneration that they received performing in palace theatres for the Ranas (Rijal, 2015). In the year 1951 after the fall of the century-old oligarch, artists saw a glimmer of hope in taking up theatre as a sustainable and survivable profession.

The second distinct epoch of Nepali theatre, marked after the fall of the Rana rule, began in a rather disparaging manner. Only nine years after Nepal earned its democracy from the tyranny, it entered into another political turmoil of the Panchayat (Party-less) system, which lasted for thirty years (1960-1990). This system, foisted by the Shah king, was no different than its preceding oligarchy. Not only did the monocratic governance curbed artistic freedom 


\section{Nepal Journal of Multidisciplinary Research (NJMR) ISSN: 2645-8470 (Paper) Volume 2, No. 3 \\ September 2019 \\ ISSN: 2705-4691 (Online)}

through censorship and close administrative vigilance, but also maintained a total control over all resources necessary for a theatre presentation. Theatre practitioners in Nepal, during that period, didn't find adequate motivation in order to establish a viable profession out of what they were already doing. They instead utilized theatre as a vehicle to create sociopolitical awareness and support the prodemocracy movement (Davis, 2010). As a culmination of such protest-oriented plays, Nepali theatre also witnessed the coining of street theatre in Nepal, which eventually became an effective catalyst in defeating the autocratic regime. Since then, street theatre became, and still is, a crucial income generating mechanism for many theatre artists.

The final chapter, and the relatively lucrative one for contemporary Nepali theatre, can be noted as the aftermath of the establishment of Aarohan Gurukul. In the year 2002, Gurukul became the first theatre company to build their theatre infrastructure, which accommodated facilities like theatre halls, library, cafeteria, and workshop hall (Davis, 2019). For numerous theatre aspirants as well as followers, this success story came as a silver lining amidst economical hardships. Throughout its ten-year active operation, the institution was able to stage plays regularly, organize the Kathmandu International Theatre Festival, and initiate theatre trainings for budding artists, marking an exciting period for contemporary Nepali theatre. Conversely, the volume of business transactions of these operators wasn't selfsufficient and no specific business/marketing practices were adopted.

The niched audience base for contemporary theatre in Kathmandu wasn't sizeable enough for theatre makers like Gurukul to earn operating profits in order survive in the market. Hence, the group, although they had ticket selling as a revenue-generating module, had to resort to donors and international non-governmental organizations (INGOs) for survival (Rijal, 2015).

Following the footsteps of Gurukul, several other theatrical institutions invested in establishing theatre structures. As of now, the theatre scene in Kathmandu is majorly run by five independent theatres: Mandala Theatre, Shilpee Theatre, Sarwanam Theatre, Kausi Theatre and Theatre Mall, the last two established their premises in 2018 (Rijal, 2015; The Kathmandu Post, 2019). These institutions, at the helm of the creative staging in Kathmandu, have sporadically garnered financial benefits too. Plays like Rashomon, Bathtub, Court Martial, Jokhana, to name a few, have in fact crossed the million rupees mark in terms of box-office collection (Rijal, 2015; Kanitpur, 2019).

The proliferation of numerous independent theatres and infrequent box office triumphs, however, does not necessarily allude to the profitability and sustainability of Nepali theatre. Few of established theatres have ceased to operate - mainly due to initial investment capitals, uninventive business and marketing focus, and myopic strategic visions. The closing of Theatre Village in 2016 and of Theatre Mall in the following year raises pertinent question about the economic and business viability of theatres in Kathmandu (Bhattarai, 2018). On the other hand, the makers and practitioners, who are pressed by financial adversities, are leaving theatre for other rewarding professions, such as the gradually growing cinema industry (Mottin, 2018).

Accumulating all these incidental factors and existing approaches practiced in running the theatre industry in Nepal, one can comprehend the vitality of an appropriate strategic mix in order to safeguard the future of the theatre art form.

\section{Overdependence on donors and INGOs: A failed financial model}




\section{Nepal Journal of Multidisciplinary Research (NJMR) ISSN: 2645-8470 (Paper) Volume 2, No. 3 \\ September 2019 \\ ISSN: 2705-4691 (Online)}

The presence of a donor-allied praxis is ubiquitous in the present context. Especially, developing countries have been at the receiving end of these mechanisms as primary beneficiaries (Wood, 2005). Apart from key sectors like agriculture, health, education, financial aid intervention in cultural and art related practice has been quite evident.

The perilous relationship between Nepali theatre and its donor agencies can be witnessed through the unfortunate fate of Aarohan Gurukul, the pioneer of contemporary theatre in Nepal. Social Anthropologist Monica Mottin (2007) astutely observes the overdependence of Nepali theatre on donor agencies. In her paper Dramas for social change: theatre for development or the development of theatre, she presents:

A well-established theatre director asserted that $75 \%$ of his group's budget is coming from foreign funding, $10 \%$ from development theatre and the rest from tickets. Actors accuse that long-term planning is difficult since if funding stops, not only will the group have to stop performing but also other groups that depend on it for performance spaces and facilities will face hardship.

Parallel to its proscenium operations in the years between 2002-2012, similar to other theatre groups, Gurukul also was heavily dependent on international organizations like MS Nepal and Norwegian Embassy and other Danish INGOs (Mottin, 2018; Rijal, 2015). Utilizing project funds earned from these foreign entities, Gurukul, along with other several theatre counterparts, invested their time and energy in preparing and executing development plays - travelling to various parts of the country. Most of these plays simply carried the topical agendas of the funders, or the intermediate organization handling those funds. It is in this period that a surge of street theatre, forum theatre (also known as kachahari) and community theatre came to the fore. While these development-oriented plays lacked aesthetic and artistic value compared to the proscenium plays (Subedi, 2006, p. 242), they helped artists and theatre houses to survive at a time when earning regularly was a farfetched dream for many. However, when many theatres joined the bandwagon and exploited the donor aids to repletion, the market for foreign funds saturated.

Another reason for the downsizing of the funds is related to the selfish nature of donor alliance. The donating institutions are more concerned about getting their vested interest fulfilled rather than sparing thoughts for the holistic development of Nepali theatre. These ulterior motives often hinder the creative and aesthetic attributes of theatre, even making it appear as a preaching and propagandistic tool for the patrons (Mottin, 2018).

The disastrous result of this overdependence came in the year 2012, as Gurukul shut down all of its operations due to increasing monetary pressures and liabilities. The organization's mission to try to reduce foreign aid in sustaining theatre turned out to be an ambitious errand, leading the effervescent young company to a premature decline (Rijal, 2015).

The downfall of various theatre groups in such quick succession signifies that there's no perpetuity for theatres in the donor funded arrangement model. And although intermittent funding might be available in the days to come, theatres have to be inventive and proactive enough to figure out self-sustaining commercial models to guarantee success in the long run.

\section{Theatre as a Service Industry}

The need of the hour for Nepali theatre industry is to move towards a more sustainable business setup, lowering its dependence on donors and/or the state. For this to happen, it needs to collectively work on devising various interdisciplinary business strategies that could 


\section{Nepal Journal of Multidisciplinary Research (NJMR) ISSN: 2645-8470 (Paper) Volume 2, No. 3 \\ September 2019 \\ ISSN: 2705-4691 (Online)}

eventually fuel its self-reliance potential in a rapidly growing competitive market of arts and entertainment.

Toffler (1964), with his early works on The Culture Consumers, has accentuated on the need of treating theatre as a service industry. While doing so, he opened avenues for future researchers who could invest efforts in synthesizing the core nature of theatre services with appropriate crosscutting strategic models. Adding up to Toffler's initiation, Mclean (1997) believes that since the five general characteristics of a service industry (intangibility, perishability, heterogeneity, inseparability and lack of ownership) are applicable to the context of cultural organizations, theatre institutions can also be suitably recognized as part of a service sector.

One strategic approach that has been leveraging on the service industry dimension of theatre since then is the marketing of theatre offerings. A considerable number of researchers and service practitioners have realized that meticulously planned marketing of companies involved with cultural and art products is the singular way out of this financial trappings. Kotler and Scheff (1997) opine that marketing models are vital for theatre institutions to guarantee economic and business success. Similarly, Boorsma and Chiaravalloti (2010) have concluded that the need for marketing strategies is the outcome of the competitive pressure that theatres have been currently facing in the entertainment industry.

Out of the many definitions that marketing has had in the past, Kotler and American Marketing Association (AMA) $(2009 ; 2015)$ define it in a relatively common denomination. Both meanings present cohesion in explaining how marketing concentrates on value creation for fulfilling the needs and wants of a targeted consumer base. Furthermore, Bao and Shanygina (2013) consolidate the same idea by stressing that all of this is done to eventually build a lasting bonding with the consumer.

\section{Application of Marketing Mix Model in Nepali Theatre Scenario}

The extant literature confers that the implementation of marketing in any entity happens through a set of interconnected strategies called marketing mix. Propounded by Neil Borden in the 1950s (American Marketing Association, 2017), the concept of marketing mix has gone through multiple abridging in the past. As of now, academic scholars have popularized the idea of 4Ps-- namely, Product, Price, Place, and Promotions -- under the scheme of marketing mix.

\section{Developing Audience-Centric Product Offerings}

According to Colbert (1993), cultural organizations that mostly offer intangible art and culture products shouldn't primarily focus on the needs and wants of their potential audiences (consumers). Contrary to the much-revered idea of Colbert, Bernstein (2007) stresses on a more contemporary mindset by putting the audience perceptions, wants and needs at the core of any theatre business. He claims that deficiency in audience focus while designing offerings has been creating hindrances in the business of theatre.

The rising necessity to cater audience's specific requirements can also be attributed to the increasing entertainment options available to the audience (Orend \& Keegan, 2019). The younger generations of audience, who are more frequent visitors to the theatre, have access to multiple channels of entertainment such as cinemas, online streaming platform, gaming, outdoor adventure etc. And within such speedily changing platforms of engagement, theatre faces a monumental challenge to fit itself in people's preference list. 


\section{Nepal Journal of Multidisciplinary Research (NJMR) ISSN: 2645-8470 (Paper) Volume 2, No. $3 \quad$ September 2019 ISSN: 2705-4691 (Online)}

Understanding the ethos of audience-centric product, Nepali theatre can embrace tactical product strategies to tailor its product as per the diaspora of the audience.

- The preliminary step that theatre companies in Nepal should undertake is tracing the consumer feedback and preferences. So far, Nepali theatres rely only on a verbal and casual feedback from the audience. This informality should be brought into a formal domain by properly documenting audiences' responses through questionnaires, videography and other interview procedures. Maintaining a database of loyal and potential consumers will help these service providers to conveniently reach out to audiences for better product offerings. (Bernstein, 2007). The solicitation of visitors' information will further help groups to better design their art products in a more market-centric way. One success story of this method of product design is Starlight Theatre's play -- Footloose. Upon annually tracking and investigating audience preferences, ticket buying behavior and pertinent trends, the theatre was able to stage Footloose, a play that was most sought by audiences in the vicinity (Pierce, 2016).

- Once the institutions are adept in properly segmenting their audience categories, they can focus on aligning product-audience match. Although it is understood that every play cannot achieve high box-office figures, makers can identify a portfolio of varieties of dramas, and also can rank them based upon their revenue generating potential. Rijal's (2017) study on the Nepali audiences' facets has somewhat shown a trend, which states that plays based on school, college or University curriculum will raise more interest in audiences, who usually are eager to see their course text get adapted on to the stage. Sensing this opportunity, several institutions can think of adapting renowned plays such as Miss Julie, Antigone, The Apple Cart, just to name a few, which are part of the English Literature course in Nepal (Rijal, 2017). Integrating course embedded plays into their calendars on an annual basis can help theatre to extend itself to newer audience base, and to harvest benefits from the steady cash inflows.

- Many scholars point out that theatre can create an interdisciplinary coalition with other complimentary industries. For instance, Bennett (2005) argues how theatre culture can be used as a tool for destination marketing and branding. The expanding interests of corporate institutions to tap into this opportunity also reveal the viability of the strategic idea. Since Visit Nepal 2020, an initiative led by the Nepal Government, is around the corner, theatre establishments can think about getting into a strategic alliance or collaboration with the state, tour operators, and hotel owners to push their art products to foreign spectators. Convincing tour operators and travel agents to add theatre shows and visits in their service offering will undoubtedly boost the sales of these art institutions.

\section{Calibrating Prices as per Contexts}

Even though the average ticket price of a theatre show in Nepal has almost equaled to that of cinemas, theatre practitioners still believe that revenue streams generated from solely selling tickets aren't adequate to bear the theatre expenses (Rijal, 2015). What is more daunting for theatres is to operate in a price parity level with movie halls, because, given the state of the art, it cannot compete with cinemas in areas like seating amenities, auxiliary services, and parking facilities. This compels Nepali theatres to brainstorm flexible and advantageous pricing strategies for each performance. 


\section{Nepal Journal of Multidisciplinary Research (NJMR) ISSN: 2645-8470 (Paper) Volume 2, No. 3 \\ September 2019 \\ ISSN: 2705-4691 (Online)}

- Introducing dynamic pricing mechanisms:

Dynamic pricing, which garnered immediate success in sectors like airlines, hotels, cruises, among others, is a practice through which businesses set prices based on the demand and demand-determinants of the service or product offered (Sahay, 2017). Theatre institutions in Nepal have been practicing a rather rigid price-structuring so far. Barring concessions to students, there are no other flexible offering in display. Rijal (2015) notes that the prices of theatre institutions average around NPR 200/- for general admission and NPR 100/- for students. (The price has gone up to NPR 500/(front row)/ NPR 300/- (general admissions, and NPR 200/- for students). The increased price rate per performance is as high as for a film screened in a multiplex movie hall. To combat the inevitability of price rises and its paradoxical effect on attendees' inflow, theatre companies can bring in ranged pricing policy depending upon the occasion and scheduling of the play. Discounts on advance reservation and payments, varied price rates for weekends and weekdays, and concessions for bulk ticket purchases are few viable options that the industry can immediately implement. Moreover, attenuating ticket prices for regular audiences through loyalty schemes can lessen the payment burden on aficionados as well as attract more number of audiences.

- Value based psychological pricing

Colbert (2003) elucidates that pricing in cultural and/or art products are psychologically driven. Since the intangibility of the service often makes it difficult to quantify, audiences' perception and top of the mind positioning influence their decisions. This dimension supplies ample breadth to theatre practitioners in order to practice value based pricing, a method, which germinates from the value perceived by the consumer.

Theatre players in Nepal can rely on this method in order to categorize the pricing of the plays based on their scale and creator. Performances that require substantial initial capital outlay or those that are created by renowned local directors can be priced comparatively higher than the rest. As per the psychological pricing, these price hikes, aided by justifiable reasons, won't result in discouraging the audiences to pay for an increased rate.

\section{Employing Ways to Better Utilize Facilities}

It is mostly argued that a service product, due to its characteristic of inseparability -- a condition where production and consumption cannot be separated-- needs to be consumed wherever and whenever produced (Zeithaml, Bitner \& Gremler, 2009). Theatre is no different to this criterion; therefore, the infrastructure of theatre in disseminating a product (performance) remains substantial. People in Nepali theatre are well acquainted with this strategy, as most of the theatre houses depend on hall rentals for basic income flow (Rijal, 2015). Besides this, the idea of live streaming or electronic dissemination of theatre performances can also bring an innovative change in the ways of operation. This can be exemplified by the case of Royal Opera House's decision to enter the DVD market in order to expand the reach of their offerings (Walmsley, 2011).

The place element of the marketing mix has also been experimented and influenced by the concept of ancillary services (Walmsley, 2011). The auxiliary services like parking facilities, seating arrangements and comfort, location convenience of the buildings are other factors to be closely considered by theatre houses while designing products. Walmsley also states that 


\section{Nepal Journal of Multidisciplinary Research (NJMR) ISSN: 2645-8470 (Paper) Volume 2, No. 3 \\ September 2019 \\ ISSN: 2705-4691 (Online)}

site-specific and open amphitheater performance adds value to the viewing experience. Taking cues from the idea of site theatre, contemporary players in Nepal can explore the possibilities to synergize the historical heritage sites with theatre performance. During the staging of Arjuna's Dilemma, a fusion of opera and theatre, Deborah Merola introduced this the concept of blending locale and the subject. For the first time in Nepal, audiences got to witness an open-air fused opera performance in a museum courtyard, which enhanced the audience experience (Basnet, 2017).

\section{Formulating Promotional Strategies in Coordination with Corporate Houses.}

Studies have illustrated that most of the privately owned cultural organizations (private museum) fall behind in promotions and marketing campaigns mainly due to the shortage in marketing budget (Mejon et al, 2004). Rijal (2015) concurs with the scenario, as he mentions that Nepali theatre, struggling with a constricted budget plan, is more inclined towards the free media -- also known as 'word of mouth' publicity. To strengthen the significance of this argument, Bernstein (2007) prioritizes communication as the pinnacle of marketing activities that a cultural organization has to undertake. So, in order to cope with the dichotomy of rising need of communication and depleting promotional budget, Nepali theatre has no other immediate choices than to be inventive in identifying promotional strategies that can open up profitable avenues to expand its business.

- Hosting for Product Placement Strategies.

The utility of product placement -- through which corporates place their branded products within the content of media programs-- has been tested and validated all over the world (Homer, 2009). While the popularity of this strategy is evident in Televisions and Films, it has not been tried in the field of dramas and theatre. Researches demonstrate that moderately repeated placements that are done in a subtler manner are more likely to enhance brand attitude in audiences (Homer, 2009). Based on such gainful underpinnings of product placement, theatres in Nepal can persuade national/international brands to partake in a mutually beneficial partnership to promote each other. Through this strategy, companies can configure product placements in the form of stagecraft, props, costumes or merchandizes, all of them available within the premise of a theatre house. For theatre, the benefits of this strategy come in twofold: first, theatre can leverage on the expansive network of brands and corporate houses in order to promote their event. Next to that, it also can earn remunerations from brands, which can be further invested in carrying out extensive promotions of the performance.

- Intensifying Social Media Posts.

It has already been discussed that the most effective and affordable means of communication for theatre are the ones that are relatively free of cost. In order to educate and persuade audience, the use of social media marketing can be a tactical tool for theatre operators (Leko-Šimić \& Biloš, 2017). Timely and relevant posts regarding the new performances, artists' stories, issues of Nepali theatre and process involved in making a theatre performance can intensify the interests of the younger audience, who are more keen in the virtual dissemination of such information.

\section{Conclusions}

Never has the theatre industry in Nepal been so invigorating like it is now. The tremendous amount of faith shown by the extending niche of audience, specially the younger patrons, has been motivating and inspiring for the industry. At the same time, the proliferation of theatre groups also insinuates an optimistic view for the art form. For the past decade, Nepali theatre 


\section{Nepal Journal of Multidisciplinary Research (NJMR) ISSN: 2645-8470 (Paper) Volume 2, No. 3 \\ September 2019 \\ ISSN: 2705-4691 (Online)}

has been striding forward, both qualitatively and quantitatively. Battling creative droughts, business lows and fruitless government vows, practitioners have relentlessly and vigorously proven themselves, time and again. However, underneath this adamancy of the workforce lies pathos of people who've given their life and soul to the sacrosanct art form. The future of Nepali theatre, hinged on these tireless shoulders, appears to be bleak, businesswise. And when all dependency models, be it with the state or the donors, have mostly failed, Nepali theatre now needs to immediately plan for a more self-sufficient and profitable configuration. People at chief positions need to realize the crosscutting implication of business and marketing strategies on theatre operations. Leveraging on a meticulously planned product design, ticket-pricing policies, facility usage and an effective communication model, theatres can overhaul the current stagnant modus operandi in running a service industry. To make all of this happen, reformation in strategic thinking, policymaking and managerial execution is consequential. But the most important shift should come in the mindset of people, whereby decision makers will start to prioritize business and marketing strategies as equally as the arts.

\section{References}

American Marketing Association. (2017). What is Marketing? — The Definition of Marketing - AMA. [online] Available at: https://www.ama.org/the-definition-ofmarketing-what-is-marketing/ [Accessed 10 Oct. 2019].

Bao, X. and Shanygina, D. (2013). The Impact of Microblog Marketing on Consumer Attitude and Behavior. Applied Mechanics and Materials, 427-429, pp.2656-2659.

Basnet, S. (2016). Bhagvad Gita as opera. Nepali Times. Retrieved from http://archive.nepalitimes.com/article/Nepali-Times-Buzz/Bhagvad-Gita-asopera,3236

Bennett, S. (2005). Theatre/Tourism. Theatre Journal, 57(3), 407-428. doi: $10.1353 / \mathrm{tj} .2005 .0087$

Bernstein, J. (2007). Arts Marketing Insights. Jossey-Bass.

Bhattarai, S. (2018). All the men and women merely players. Nepali Times. Retrieved from https://www.nepalitimes.com/here-now/all-the-men-and-women-merely-players/

Boorsma, M. and Chiaravalloti, F. (2010). Arts Marketing Performance: An ArtisticMission-Led Approach to Evaluation. The Journal of Arts Management, Law, and Society, 40(4), pp.297-317.

Colbert, F. (2003). Entrepreneurship and leadership in marketing the arts. International Journal Of Arts Management, 6(1), 30-39.

Davis, C. (2010). Drama of Disillusionment: Nepal's Theatre, 1990-2006. Asian Theatre Journal, 27(1), 23-39. doi: 10.1353/atj.2010.0016

Davis, C. (2019). Theatre of Nepal and the people who make it (pp. 145-147). Cambridge: Cambridge University Press. 


\section{Nepal Journal of Multidisciplinary Research (NJMR) ISSN: 2645-8470 (Paper) Volume 2, No. 3 \\ September 2019 ISSN: 2705-4691 (Online)}

Homer, P. (2009). Product Placements. Journal Of Advertising, 38(3), 21-32. doi: 10.2753/joa0091-3367380302

Iji, E. (2007). The Business of Theatre and the Theatre of Business. Global Journal Of Humanities, 5(1). doi: 10.4314/gjh.v5i1.29373

Kantipur. (2019). Eutai Naatak Bata 16 Lakh. Retrieved from https://ekantipur.com/entertainment/2019/05/01/155668511852699280.html

Knell, J. (2005). The Art of Dying. Intelligence Agency. Retrieved from https://www.culturehive.co.uk/wp-content/uploads/2013/10/23974643-Art-of-DyingJohn-Knell-2005_0.pdf

Kotler, P., \& Scheff, J. (1997). Standing room only: Strategies for Marketing the Performing Arts. Harvard Business School Press.

Kotler, P., Keller, K., Ang, S., Leong, S. and Tan, C. (2009). Marketing management. Pearson Prentice Hall.

Leko-Šimić, Mirna \& Biloš, Antun. (2017). Theatre Marketing: Using Websites to Attract Young Target Audience. Irish Business Journal. 10. 30-47.

Mclean, F. (1997). Marketing the museum. London: Routledge.

Mejón, J., Fransi, E., \& Johansson, A. (2004). Marketing Management in Cultural Organizations: A Case Study of Catalan Museums. International Journal of Arts Management, 6(2), 11-22. Retrieved from www.jstor.org/stable/41064816

Mottin, M. (2007). Dramas of Development: Theatre for Development or the Development ofTheatre?. Studies In Nepali History And Society (SINHAS), 12(2), 321-347.

Retrieved from https://www.academia.edu/40512940/Dramas_of_social_change_theatre_for_develop ment_or_the_development_of_theatre

Mottin, M. (2018). Rehearsing for life. Theatre for social change in Nepal (pp. 238-242). Cambridge: Cambridge University Press.

Orend, R. \& Keegan, C. (1996). Education and Arts Participation: A Study of Arts Socialization and Current Arts-Related Activities Using 1982 and 1992 SPPA Data. National Endowment for the Arts, Washington D.C.

Pierce, A. (2016). Developing A Sustainable Business Model for Theatres: A Case Study of Kansas City's Starlight Theatre (Ph.D.). University of Missouri-Columbia.

Rijal, S. (2015). Journey to the Marketplace: Contemporary Nepali Theatre in a Crossroad. Studies In Nepali History And Society(SINHAS), 20(1). Retrieved from http://www.martinchautari.org.np/files/SINHAS-Articles/SINHAS-Vol.20No.1_Commentary_Shiva-Rijal.pdf 


\section{Nepal Journal of Multidisciplinary Research (NJMR) ISSN: 2645-8470 (Paper) \\ Volume 2, No. 3 \\ September 2019 \\ ISSN: 2705-4691 (Online)}

Rijal, S. (2017). Donors, Directors and Audience: A Survey of the Performance of Plays in Nepali. Nepalese Translations, 1, 55-61. Retrieved from http://translators.org.np/uploaded/ckeditors/files/10_SRijal_Donors.pdf

Sahay, A. (2007). How to reap higher profits with dynamic pricing. MIT Sloan Management Review, 48, 53-60.

Singh, C. (2004). Rise and Growth of Anti-Rana Movement in Nepal. Proceedings of the Indian History Congress, 65, 992-1002. Retrieved from http://www.jstor.org/stable/44144808

Subedi, A. (2006). Nepali Theatre as I See It. Kathmandu: Aarohan.

The Kathmandu Post. (2019). Kausi, a new terrace-theatre in town. Retrieved from https://kathmandupost.com/art-entertainment/2018/06/21/kausi-a-new-terrace-theatrein-town

Toffler, A. (1964). The Culture Consumer: A Study of Art and Affluence in America. New York: St. Martin's Press.

Walmsley, B. (2011). Why people go to the theatre: A qualitative study of audience motivation. Journal Of Customer Behaviour, 10(4), 335-351. doi:

10.1362/147539211x13210329822545

Walmsley, B. (2011). The 21st century business model. In: Walmsley, BA, (ed.) Key Issues in the Arts and Entertainment Industry. Goodfellow. ISBN 978-1-906884-20-8

Wood, T. (2005). Village Phone Replication Manual: Creating Sustainable Access to Affordable Telecommunications for the Rural Poor, The United Nations Information and Communication Technologies Task Force, New York, NY.

Zeithaml, V., Bitner, M., \& Gremler, D. (2009). Services marketing. Tata McGraw Hill. 